Fecha de recepción: octubre 2019 Fecha de aceptación: diciembre 2019 Versión final: noviembre 2021

\section{Los cibergéneros especializados: análisis sobre la modalidad de gestión de contenidos en weblogs independientes de moda}

Gabriela Gómez del Rio *

\begin{abstract}
Resumen: Las plataformas especializadas independientes, también conocidas como weblogs emergen como producto de una práctica social (el blogging) Estas plataformas ya no son una novedad sino más bien son una necesidad del circuito de comunicación digital especializado en moda. Los weblogs ya no se agotan en su dimensión comunicativa sino que son nudos claves del entramado que conforman la red. Actualmente a partir de su análisis podrían sistematizarse tres cuestiones fundamentales: la constante en sus rasgos estilísticos, la potencialidad como generadores de contenido de calidad para la red y su modalidad de articulación en relación al circuito al que pertenecen.
\end{abstract}

Palabras clave: blog - blogger - moda - marketing de moda - emprendedores.

[Resúmenes en inglés y portugués en la página 125]

${ }^{(*)}$ Maestría en Periodismo, Universidad de Buenos Aires. Licenciada en Ciencias de Comunicación Universidad de Buenos Aires. Profesora de la Universidad de Palermo en el Área Moda y Tendencia de la Facultad de Diseño y Comunicación.

\title{
Introducción
}

Las plataformas independientes o weblogs han logrado especializarse según su área de interés, en tanto a su modalidad de gestión. Piscitelli (2005) explica que, los weblogs son páginas webs que se actualizan más que frecuentemente y su gestión no es "un collage de links o un mero agregado de remisiones a obras de terceros, sino un auténtico trabajo de pliegue de ideas y palabras donde se busca generar nuevas formas de ver" (p. 60) Los weblogs exigen a quien los gestiona la administración en su totalidad. Es decir que, los blogueros se ocupan del circuito completo del contenido que generan, esto es: la producción, la circulación y están atentos a su recepción. Un weblog es un espacio protegido en donde el bloguero es productor general del contenido que se publica. Esta particularidad adquiere relevancia porque el bloguero deber adherir al ritmo mismo que exige la red.

La interacción ha dado lugar a diferentes nominaciones según el contexto o el modo en el que se dé; por ejemplo, de Rosnay (2002) explica que: 
Las lógicas de interacción abren nuevos espacios. Después de la logósfera del lenguaje, limitada por el tiempo y el espacio, de la grafosfera de la escritura, no limitada ni el tiempo ni en el espacio, y de la mediasfera de la televisión, entramos en la ciberesfera, la de las comunicaciones eléctricas (p. 31).

Entre estos espacios de interacción se encuentra también la blogósfera, que se considera como un espacio social mediado tecnológicamente donde el entramado de los weblogs y por ende de blogueros interactúan en la red. Además, puede concebirse como una red sociotécnica en la que lo social se construye a través de lo técnico y lo técnico adquiere un sentido tan intensamente social que resulta imposible distinguir lo uno de lo otro, lo que es estrictamente técnico de lo que es social (Bijker, 1989, 1995, citado en Estalella, 2005). La blogósfera sucede en la virtualidad de la red; en este sentido Alberich i Pascual (2004) explica que: "la virtualidad designa entidades desvinculadas de una única actualización y admite manifestaciones en múltiples formas y situaciones gracias a su capacidad de actualizarse en cualquier nodo del espacio informático dotado de conectividad" (p. 60). Toda esta particularidad sobre el hacer en la virtualidad queda enmarcada en lo que se denomina como ciberespacio en donde los fragmentos de diferentes discursos como la música y otros audios, textos, imágenes, videoclips, etc., confrontan elementos 'concretos' que producen un significado 'abstracto' (Zizek, 2010).

El bloguero como generador del contenido que postea deja fluir la "textualidad digital. El hipertexto reconfigura-reescribe- al autor de varias maneras evidentes. La figura del escritor en hipertexto se acerca a la del lector, aunque no se funda completamente en ella; las funciones del escritor y del lector se entrelazan más estrechamente que en cualquier otro momento", explica Alberich i Pascual (2004) e incluso el autor señala que los entornos digitales posibilitan la creación colectiva de obras grupales que dan lugar a un sistema de posibilidades narrativas. La figura del bloguero se podría asimilar a la figura del autor de narrativa electrónica que, según el autor:

Es un coreógrafo que proporciona los ritmos, el contexto, y los pasos que se pueden bailar. El usuario, ya sea navegador, protagonista, explorador o constructor, utiliza este repertorio de pasos y ritmos posibles para improvisar un baile entre muchas posibilidades que el autor ya digital ha preparado (p. 67).

Bajo estas características se podría entender que los webglos, si bien cada uno profesa su propio estilo, de base compartirían un estilo común propio del blogging, es por eso que se podrían comprender como un género en sí mismo; porque como señala Bajtin (1979): "donde existe un estilo, existe un género" (p. 254). Una de las particularidades del estilo del blogging, y en sí del texto online, sería el hipertexto. Estos nuevos relatos (Martín Barbero, 2007), su alimentan de la cultura del zapping, como fuente de cristalización de su estilo.

Los weblogs han recorrido un largo camino. Desde pensarse a sí mismos como las herramientas más renovadoras de la red (...) hasta convertirse en un formato conocido o estandarizado. (...), más que seguir analizándolos, entusiasta y críticamente, es tratar de sistematizar sus aportes (Piscitelli, 2005, p. 63). 
Es decir que, el análisis sobre estas plataformas independientes ya no radica en éstas como novedad sino que podrían analizarse como nuevos géneros digitales que a su vez activan nuevos roles, como por ejemplo: el rol del blogger.

La moda como fenómeno ha inundado cada uno de los aspectos que inciden en la cotidianeidad, pero para este trabajo es fundamental entender la diferencia entre la Moda y las modas. Porque, como señala Saulquin (2006):

Es habitual considerar la moda de las vestimentas como símbolo de la moda propiamente dicha, ya que su cambio y transformación están representados, por excelencia, por el vestido, cuya característica saliente es la alta rotación. En ese sentido, la moda del vestido es entendida como el cambio periódico de vestimenta en grandes grupos de población, de acuerdo a tendencias orquestadas por los centros de producción (p. 12).

La moda y más precisamente el vestido puede comprenderse como una producción de sentido y sus particularidades como condensaciones del mismo (Sexe, 2007) La modas permiten a quienes adhieren o no a ellas a constituirse dentro su núcleo, es decir que, por adopción o por omisión dan al sujeto parámetros descriptivos sobre sí mismo. Este intercambio simbólico es constante; Bourdieu (1979) expone que "La moda es la resultante de esta correspondencia entre la producción diferencial de los bienes y la producción diferencial de los gustos que halla su espacio en las luchas simbólicas entre clases". Las modas parecieran surgir de intercambios naturales que mutan de estación a estación sin más, pero encubren el trabajo anterior de cinco años en donde se delimita cada mínimo de detalle que contendrán en la temporada (Gómez del Río, 2009). Y estos bienes son los que forman parte del contenido que puede verse en las plataformas independientes especializadas quienes se encargan de trabajar sobre el vestido escrito (Barthes, 2003).

Se puntualizará sobre el concepto de la moda, ya no entendida como la simple manifestación de las vanidades del ser humano sino como una de las instituciones características de Occidente (Barreiro, 1998). Pero, en esta época regida por la digitalización del consumo, la moda es algo más que un ámbito profesional, es una corte y todos sus personajes, "es Versalles, versión globalizada y mucho dinero" (Lannelongue, 1998, p. 15).

El contenido de los weblogs se rige bajo la lógica del sistema de la moda que contiene en sí el imaginario de lo efímero como valor del producto (Lipovestky, 1994) El mismo lleva implícito la historia de la siluetas y tipologías que dan estilo a la indumentaria contemporánea (Lever, 1995). Quienes gestionan contenidos en plataformas digitales hacen del vestido real un párrafo que lleva el código impreso para los usuarios actuales (Lurie, 1994) y dan relevancia a través de sus post a una de las características fundamentales de los productos propios del rubro, que es que "toman sentido real una vez anclados en el cuerpo" (Saltzman, 1994). Es decir que, la gestión del contenido en los weblogs exige que se piense al objeto (moda) en una situación de comunicación (weblog) estableciendo así un tipo de situación discursiva (Sexe, 2007) que reúne determinadas modalidades propias para que tenga lugar en la red. 


\section{Bloggers y un nuevo marco de referencia}

La inclusión de un nuevo medio implica la ampliación del marco de referencia tanto horizontal como vertical. Y por ende, amplía la incorporación de nuevos roles. Esto pasó en la construcción de la información en el ciberespacio. La entrada de los bloggers al circuito de la información generó una tensión entre periodistas y bloggers. Los primeros en pie de lucha por el espacio que aparentemente le estaba siendo usurpado, sin poder observar que son dos actividades totalmente diferentes. Los bloggers no son periodistas y los periodistas no son bloggers.

Hace un poco más de dos años el periodista español -especializado en moda- Agustín Velasco, publicaba en su columna semanal del diario eleconomista.es una entrevista que le había realizado una estudiante de periodismo -de DukeUniversity- con el afán de descubrir los cambios a los que debían enfrentar los periodistas no sólo ante el avance de las nuevas tecnologías sino también de aparición -en el rubro- de los nuevos roles, como el ahora conocido: blogger. Ante la pregunta sobre si Velasco era bloguero, él respondió:

No, yo soy un periodista con un blog, que es muy diferente. Es algo que siempre recalco. De hecho cuando me mandan invitaciones a eventos para blogueros las desestimo. No es un gesto de esnobismo, en absoluto. Creo que el bloguero tiene su función dentro de este sistema, pero yo simplemente, como periodista, tengo otra función distinta.

Esta simple respuesta, a primera vista, cristaliza cuestiones propias de las condiciones de producción del discurso de la moda, de un tiempo a esta parte, sobre las pasarelas de la virtualidad.

\section{a. La moda, del papel al bit}

Desde fines del siglo XIX las revistas especializadas, y con éstas los periodistas y editores de renombre, enseñaron a sus lectores las características de la moda y el modo en el que debían entenderla a través del contrato de lectura estipulado (Verón, 2004) Con el advenimiento, durante la primera década del SXX, de la mujer como consumidora, el discurso de la moda no hizo más que afianzar su propósito como motor del sistema de la moda. La lectora que supone la revista femenina asume un rol de niña, pero no por el material que la revista pone a su alcance, sino por la modalidad enunciativa que se pone en juego a la hora de presentar cualquier cosa que se encuentre dentro de ese formato. Su lectora se concibe enunciativamente como niña, pero comercialmente como adulta.

La reproducción de las arbitrariedades culturales que presentan las publicaciones, mediante la relación asimétrica que implicaría el rol de autoridad pedagógica de la publicación especializada frente a su rol de educada de su lectora constituyen una de los mecanismos determinantes por los que se haya asegurada la reproducción social que se define como reproducción de la estructura de las relaciones de fuerza entre las clases, siendo el valor del capital cultural que promueven el que determinará en el mercado el valor económico 
o simbólico, es decir de su capital cultural, al que la lectora (en general) de las revistas especializadas no pertenece pero accede mediante lo que la publicación le enseña (Bourdiey y Passeron, 1981) Proceso que tiene su génesis en el contrato de lectura estipulado, como así también en el género al que pertenece la publicación.

Contar la moda es más que representar la prenda en sí para las lectoras, la moda es un conjunto que connota infinidad de variables posibles. Barthes (2005) entiende a la moda como sistema, y ésta deja de poseer un carácter pobre cuando se analiza como discurso. La moda sólo se hace tangible a partir de la discursividad, cualquiera sea el soporte de ésta, que se genera sobre la misma, de lo contario cae automáticamente en la carencia que remite la prenda en sí (Gómez del Río, 2010, p. 17).

\section{b. Nuevos servicios online}

Al mismo tiempo en el que las revistas especializadas estaban abocadas en subir su contenido en la red, PyraLabs crea el servicio Blogger en el año 1998. Esta empresa es la primera en acuñar el concepto blog y por ende blogger. Se lanza el servicio en el año 1999 al público y finalmente lo adquiere Google en el año 2003. El servicio Blogger permite crear y publicar bitácoras en línea, permitiéndole al usuario no tener que escribir ningún código HTML o instalar programas de servidor o de scripting. Posibilitando una gestión rápida y de fácil acceso. El año 2004, el servicio Blogger fue relanzado haciéndolo aún más visible para aquellos interesados en generar su propios contenidos. En aquel entonces, el territorio de la blogósfera como espacio de interacción de los bloggers fue haciéndose de su jerarquía dentro del Ciberespacio. La blogósfera poseía el ecosistema de comunidad, esto quiere decir que sus células se nutrían del alimento, primordial de la web: compartir. Los blogs fueron creciendo bajo la premisa de la experiencia compartida en comunidades nucleadas por un tema en común, cuestión que se expandió a un modo comunicar dejando atrás la noción de comunidad como un circuito cerrado.

\section{c. La glocalización como modo}

La noción de globalización es una noción que nos llega del campo del management y del marketing y se usa para designar todos los fenómenos de internalización de los productos culturales, los intercambios culturales, etc. Pero los bloggers dieron al discurso de la moda su punto de glocalización (globalización y localización), término que explica Mattelart (2002) al referirse al contexto en red, es decir que siguiendo esta lógica -los bloggers- lograron fucionar en sus post: lo local, lo global y lo nacional, sacándole provecho a al hecho de que no se puede ser global si no es a la vez local y nacional (pp. 41-42).

Los blogs se viralizaron en la red, y la el rubro de la moda no fue la excepción. Los blogs de moda comenzaron a circular en la red y tuvieron un envión -aún mayor- con lo que se conoce como la web 2.0. La web 2.0 se populariza en el año 2006 con introducción de las plataformas de las redes sociales, en la Argentina este punto de inflexión se produjo recién en el 2009. La web 2.0 se caracteriza por la interacción producto de la rotación del 
contenido que se genera, espontáneamente o no, a través de las redes sociales. Las lógicas de la interacción producto de las comunicaciones electrónicas gestionan nuevos espacios como la ciberesfera que, como explica de Rosnay (2002), devienen "después de la logósfera del lenguaje, limitada por el tiempo y el espacio, de la grafósfera de la escritura, no limitada ni el tiempo ni en el espacio, y de la mediásfera de la televisión...” (p. 31). La moda, a través de los blogs, comenzó a contarse a través de voces varias que fueron adquiriendo autoridad en el área producto de la cantidad de seguidores y lectores ávidos de seguir cada nueva publicación en tiempo real.

\section{d. Se abre el juego en los procesos de producción}

Ante el auge de los blogs de moda, las revistas especializadas comenzaron a sentir, en su propio proceso de producción, circulación y consumo de contenidos online especializados el fenómeno que señala Castells (2007) cuando asegura que "internet es un medio de comunicación local-global que permite 'desintermediar' los medios de comunicación masivos" (p. 177). Es un espacio genérico, no particular como explica Lash (2005, p. 52). El sistema de la moda también estaba siendo reformulado por la revitalización de las identidades y la revolución de las tecnicidades, como asegura Martín-Barbero (2007) al referirse a los procesos que atraviesan el lugar de la cultura de la sociedad (p. 72).

Más de cien años de aprendizaje sobre aquello que es moda bastaron para que el hasta ahora lector se convierta en productor de contenido online especializado. Se podría pensar que, a su modo, los bloggers son prosumers como describe Mattelart (2002), es decir que ya no sólo consumidores del discurso de la moda como producto sino que están integrados al proceso de producción del mismo (p. 41). Presumers que se embarcan en el rol de bloggers para diferenciarse y no diluirse en la masa como define Saulquin (2010) al referirse sobre este fenómeno, cuestión primordial en el mundo la moda que lleva a la distinción como bandera.

\section{e. Los blogs como contenido especializado de consulta}

La cristalización del blog como plataforma válida de información modificó el modo en el que se construye el contenido para su lectura. La multidireccionalidad en relación a la usabilidad de la bitácoras y la hipertextualidad en relación a las características de su lectura son ejes paradigmáticos que caracterizan cada uno de los post de un blog cualquiera sea el tema sobre el que trabaje.

Podría pensarse que los blogs han delimitado nuevas modalidades de escritura, en términos de Barbero (2007) el lugar de la cultura cambia producto de la mediatización tecnológica (Echeverría, 1999) haciendo que la comunicación deje de ser meramente instrumental para convertirse en estructural dejando de remitir a uno aparatos para definirse como nuevos parámetros de percepción y de lenguajes abriéndose así a nuevas sensibilidades (p. 73). Ratificando así que si hay nuevas modalidades de escritura, entonces hay nuevas modalidades de lectura como señala García Canclini (2007, pp. 83-84). 
Actualmente, los blogs son más que auténticos diarios online como señala Molina (s/f), se podría confirmar que son instantes online, que se han ido sofisticando y profesionalizando. Se han convertido en material de consulta de periodistas como asegura Technorati (2012), quienes -como Velasco- tienen su propio blog, ya sea en el propio diario donde trabajan o de modo independiente. Además, de ser un eslabón fundamental en campañas de marketing online y como refuerzo de discursos corporativos. Aunque ante la pregunta de la estudiante a Velasco si leí blogs, éste respondió: "No. Son muy pocos los que realmente tienen una calidad que a mí, como profesional del medio, pueda aportarme algo. Yo devoro información, no opinión". Dejando en claro la tensión que hay entre ambos roles, porque -si bien los bloggers se hicieron su lugar- al tiempo de hoy no ha podido distinguirse que ambos roles son diferentes entre sí, aunque los contenga el mismo soporte.

E incluso Velasco asegura que la popularidad de los blogs se debe al cambio generacional, al consumo rápido, a la superficialidad con que se abordan los temas de moda, a la exacerbación de imágenes, sin reparar en que lo que ha cambiado es el modo en el que se construye, circula y se consume el discurso de la moda, pareciera no salirse del siglo XX, asomando su nariz -como quien no quiere la cosa- en el juego que propone el ciberespacio, que como explica Alberich i Pascual (2004) sobre la emergencia de la textualidad digital. El hipertexto reconfigura-reescribe al autor de varias maneras evidentes. La figura del escritor en hipertexto se acerca a la del lector, aunque no se funda completamente en ella; las funciones del escritor y del lector se entrelazan más estrechamente que en cualquier otro momento. El conjunto de características distintivas propias de los entornos digitales, tales como hipertextualidad, interactividad, no linealidad o estructura en red fagocitan la categoría tradicional de autor (p. 67).

La categoría tradicional es de lo que cuesta desprenderse para quienes no quieren hacerle espacio al blogger como profesional dentro de este nuevo marco de referencia que ha tomado a los blogs como herramientas válidas de comunicación y a los bloggers como comunicadores.

\section{f. Los blogs y su esencia}

Como explica Larrondo Ureta (s/f), los cambios que la técnica hipertextual introduce en la esencia del texto del post obligan a su lector a entender la redacción y los géneros en internet no sólo como un mero repertorio de técnicas y prácticas expresivas en función del hipertexto - a la manera de un mero saber aplicado sino también como un saber teórico necesario para una eficaz explotación expresiva y retórica del texto.

Los blogs podrían comprenderse como cibergéneros discursivos con estilo propio porque son, en términos de Bajtín (1979), tipos relativamente estables de enunciados, en este caso anclados en la red (p. 248). Y se asegura que cuentan con un estilo propio porque como afirma el autor, "donde existe un estilo, existe un género" (p. 254). Estilo que es víctima de transposición que, como explica Steimber (s/f), es "un movimiento complejo y significativo de la cultura, y no el efecto mecánico de la expansión de una tecnología” (p. 41). Se quiere encontrar en éstos, parámetros propios de otros géneros, como por ejemplo el 
periodístico. Búsqueda que no queda más que en definiciones vacuas ante estos nuevos géneros con estilo propio.

\section{Blogs de moda}

A continuación se establecerán las características de la primeras dos etapas que pueden definirse, en función a sus características, de los blogs de moda más relevantes en nuestro país Para dar cuenta de esto se analizará el formato de los blogs y la modalidad de la gestión de sus contenidos. También se dará cuenta de la aceptación del rol del blogger desde el mercado y la academia.

El objetivo del análisis se centra en describir su estructura, el estilo de redacción, su narrativa y otros elementos propios del contenido de los blogs de moda. Para ello, se indica el análisis de nueve categorías: a) presentación a sus lectores, b) origen del contenido, c) tipos de posts, d) estructura del texto, e) narrativa de los posts, f) Gramática y ortografía, g) número, tipo y destino de los enlaces hipertextuales, h) fomento de la participación y 11) capacidad de producción.

Los blogs de moda se pueden dividir en cuatro categorías, comprendidas como las más significativas: 1) streetstyle - blog que muestra y explica las diferentes maneras de llevar la ropa que usa, 2) beauty - blog que explica y muestra productos de belleza, 3) egoblog - el blogger se centra en mostrar la moda desde fotos que sacan de sí mismo, y 4) revistado, este última categoría de blog se denomina así por la variedad de temas -siempre sobre moda- que presenta en sus post.

El recorrido realizado por los blogs de moda, en nuestro país, se puede dividir en tres etapas. La primera etapa, entendida como: introducción, estaría delimitada entre el año 2006 y el año 2009, siendo ésta donde comienza a popularizarse la gestión y lecturas de los blogs. Para describir este periodo se seleccionó el blog de Lorena Pérez, creadora de Bloc de Moda. La segunda etapa denominada crecimiento, está impulsada por el auge de las redes sociales, e iría desde el año 2009 al año 2011, para describir este periodo se ha seleccionado el blog de AninkaTokos, creadora del blog Desde el vestidor. Y el último periodo podría enmarcase en el blog Chica Lunar, de Marou Rivero.

\subsection{Los blogs y su estructura}

Los blogs como plataformas virtuales permiten a los bloggers autogestionar su contenido en línea desde cualquier punto -donde se encuentren- que tenga conexión. En este caso, por ser pionero se describirá la plantilla de Blogger, pero Wordpress no varía en demasía su estilo plantilla, sí en los elementos externos que pueden sumarse para complejizar su administración. Pero, esa particularidad en WordPress, excede a la temática en cuestión. La estructura clásica de la plataforma de Blogger presenta 4 bloques flotantes: la cabecera, el cuerpo de las entradas, la barra lateral y el pie del blog. Al referir los bloques como flotantes, quiere decir que éstos pueden modificarse. 
En la cabecera es donde -generalmente- el blogger señala el título del blog que puede o no coincidir con la URL del mismo, es decir con su dirección web. En algunos casos, sobre todo desde finales de la etapa denominada como crecimiento, los bloggers han decidido redireccionar el dominio que la plataforma Blogger les dio por defecto, es decir .blogspot. com.ar a un dominio personalizado que generalmente es un .com.ar, pero también se pueden encontrar otros en nuestro país, como .com o .net.

La variación del tipo de dominio que se selecciona tiene que ver con el rango de búsqueda que se aspira tener. Los dominios acotados a país específicamente, como sería el .com.ar, acota de manera más específica el rango de búsqueda y así trancciona mejor las derivaciones de tráfico online. La redirección se acentuó durante este periodo porque fue entonces cuando blogger habilitó la posibilidad de hacer una redirección de manera sencilla, además los bloggers habían comenzado a tener reconocimiento y parte de la profesionalización del mismo constaba (y sigue siendo así) en tener un dominio personalizado.

La sección de las entradas posibilita modificar los datos que aparecen en la misma para que estén visibles o no, como por ejemplo: publicado por, fecha, botones para compartir en redes sociales, edición rápida, etiquetas, comentarios, enlaces a la entrada y cantidad de entradas.

Luego en la barra lateral, se pueden ir gestionando diferentes gadgets. Los gadgets son elementos de código acotado que facilita su manipulación. Estos elementos permiten al blogger sumar elementos, en el lateral de su plantilla, como: imágenes, texto, redes sociales, páginas, traductor, clima, cambio de divisa, suscripción, entre otros. Tanto la cabecera como el pie de la plantilla permiten sumar widgets, de su administración depende parte del diseño del blog.

\subsection{Contenido dinámico y estático}

Los bloggers pueden determinar contenido dinámico y estático en las plantillas de sus blogs. El contenido dinámico está dado por las entradas en sí que suben consecuente mente. Pero, también pueden generar contenido estático, éste se configura a través de la generación de páginas dentro del mismo código de su plantilla. Es decir que, por ejemplo el blogger puede generar un menú debajo de la cabecera de su blog, en donde las pestaña que ponga en juego deriven a páginas estáticas, y debajo del menú dejar que se vea el posteo de las entradas.

Las etiquetas cumplen dos funciones fundamentales; primero permiten filtrar al usuario el contenido que le interesa leer en el blog, es decir que si el usuario hace clic en la etiqueta BAFWEEK (la semana de la moda más relevante de la agenda local), el blog lo redireccionará a todas las entradas que constan de esta etiquetas. Por otro lado, las etiquetas son fundamentales porque permiten a los buscadores posicionar el contenido en un rubro determinada.

Las etiquetas pueden sumarse como widget en la barra lateral de la plantilla o en la parte del pie, y también pueden verse en el final de cada entrada. No todos los bloggers la dejan visibles. 


\section{Las redes como corroboración de reconocimiento}

Las redes sociales se han convertido en una parte fundamental del blogging porque hacen a la rotación de su contenido; porque si bien los lectores de los blogs se enteran de las novedades a través de la suscripción, es a través de las redes sociales que los bloggers exponen -desde la cocina hasta la versión acabada- la generación de su contenido. Además, para quienes están interesados en los bloggers como embajadores de sus productos, las redes sociales funcionan como indicadores de influencia de cada blog y en consecuencia del blogger en sí. A los blogger que tienen mayor cantidad de seguidores se los denomina influencers, consagrándolos así como líderes de opinión en el circuito virtual.

JoeZee, el ahora director de Yohoo Style (yahoo.com/style), quien fuera director creativo de la revista Elle (UUEE) desde enero del año 2007 a abril del año 2014. Durante el año 2011, además de trabajar como director creativo de Elle, Zee participó como anfitrión televisivo del programa Allon the line emitido por SundaceTV reproducido en Argentina por el canal de cable Glitz. En el episodio It's show time: Nicole Miller, Zee asesora a la diseñadora en su estrategia de imagen y comunicación para optimizar su presentación durante la semana de la moda en Nueva York.

En relación a la comunicación lo primero que le pregunta Zee a Miller es si trabaja con bloggers, si bien en Estados Unidos la etapa de desarrollo del blogging es diferente de lo que puede definirse en argentina, para ese entonces también se encontraba en lo que se definió como la etapa de crecimiento. A tal cuestionamiento la diseñadora se lo queda mirando, y entonces Zee comienza su acción en relación a la convocatoria de los mismos para así poder comenzar a trabajar, entre los bloggers que convoca para agilizar la comunicación de la marca es a Leandra Medine (autora del blog ManRepeller), quien para ese entonces ya era una influencer reconocida en el circuito de la moda. Actualmente, Leandra Medine tiene solamente en su cuenta de Instagram más de 1.137.000 seguidores. Otro de los puntos clave del episodio, fue cuando Zee se reúne con el departamento de marketing y les consulta si trabajan con bloggers en sus acciones, y las directivas de cuentas le contestan que no.

Una de las tareas más difíciles de Zee fue explicarle al director de la marca que en la primera fila de su desfile durante la semana de la moda en Nueva York, ya no estarán sentados los periodistas de los medios gráficos -a los que había invitado las últimas temporadas-, ahora los mejores asientos serían propiedad de los bloggers. Por último, el capítulo cierra con el éxito de la comunicación de la presentación de la colección y muestra a los bloggers convocados como verdaderos formadores de opinión.

Cuatro años después, y en este paralelo la acción que planteó Zee a Miller es moneda corriente, a los bloggers se considera como influencers en las redes sociales, y quienes están interesados en su gestión como promotores de productos y/o servicios los contratan en función no sólo de la cantidad de seguidores que tienen en las redes sociales, sino también se fijan en la cantidad de interacción que generany en el nivel de posicionamiento que tienen en los buscadores, siendo este último uno de los indicadores más importantes para las marcas que buscan posicionamiento en la red. 


\section{Más que formadores de opinión}

Los bloggers tiene su registro propio, y su poder de convocatoria es tal que las marcas los escogen para que protagonicen sus campañas. Marcas que están en la circunferencia de las marcas específicas de moda, es decir que son productos derivados. Como por ejemplo, Confort -línea suavizantes concentrados para la ropa- que convocó a tres bloggers del ámbito local para que representen las bondades del producto: Ellie Motolo, autora del blog It Style Blog, Lorena Pérez y a la China Calé, creadora del blog Mindthe Gap Chica. Elli Motolo, pertenece a la segunda generación de bloggers señalada previamente.

Parte de su presentación señala que su blog "nació en 2010 como un espacio personal en el que tenía ganas de contar mi experiencia en el mundo de la moda en primera persona. Acá comparto mis gustos e intereses". Y como blog de Aninka, podría estar entre un blog de estilo y egoblog. Por su parte, La China Cané, pertenece a la tercera etapa, su blog data del año pasado y se presenta como a sus lectoras como: "Publicista, asesora de imagen y periodista de moda por profesión. Producir moda, decorar ambientes y fashionista por elección. Madre malabarista, amante gastronómica, viajera eterna”. Ambas emplean plantillas WordPress.

Confort generó una serie de piezas para su campaña (2015) que recorrieron la gráfica, spot televisivos y las redes sociales. En Facebook, generó publicaciones en donde está la blogger como protagonista y la acompaña un texto propio del recurso publicitario que se denomina: alusión a la autoridad. Por cada blogger, la marca, publicó dos o tres piezas entre las que se distinguen imágenes y contenido multimedia. Por ejemplo, la publicación de la China Calé, publicada el 3 de Septiembre del corriente, dice: "La China Calé, de Mindthe Gap Chica, practica \#Ropaterapia a la hora de elegir qué ponerse para una cita romántica. Es clave tener una prenda que te haga sentir segura”.

El flayer de Lorena Pérez, publicado el 11 de septiembre del corriente año, dice: "Lorena Pérez, de Bloc de Moda, dice que siempre hay una prenda que nos encanta y tiene ese color que nos llena de energía”. En el caso de Ellie Motolo, la publicación, subida el 25 septiembre del corriente, dice: "Ellie Motolo, de It Style Blog, dice que para cambiar la rutina elige un look de fin de semana un martes. Practicá \#Ropaterapia con Comfort”. Vitamita, marca de indumentaria femenina, desde su colección para la temporada otoño invierno 2013, incorpora como protagonista de sus campañas a Olivia Palermo. Blogger reconocida mundialmente que sólo en su cuenta de Instagram tiene más de 2.550 .000 seguidores. El recurso de convocar bloggers, en el mundo, para protagonizar campañas publicitarias, lleva un tiempo. Por ejemplo, Falabella lanzón una campaña en el año 2012 para su temporada otoño-invierno que llamó Falabella Hoy y difundió bajo el mismo nombre a modo de hashtag (\#FalabellaHot)

Los bloggers, no sólo hacen a la comunicación de la moda, sino a lo que el negocio en sí que este sistema significa. Para Ti Colecciones publica una nota sobre su relevancia en el ámbito de la comunicación que titula: "Front row..., es de los bloggers? (abril, 2015). Su bajada asegura sobre el hacer del blogger lo siguiente: “...los bloggers están en el podio del fashion business..." La nota hace un recorrido por la práctica del blogger de moda tanto nacional como internacional. Y sobre la profesionalización de su prácticase pueden destacar dos comentarios de responsables de agencias de comunicación. 
Por un lado, Silvina Maggiani -socia fundadora de Urban Grupo de Comunicación- afirma que: "Las blogueras tienen que saber conversar, manejar muy bien el feedback con el público, y tener mucha chispa en pocos caracteres. Son habilidades que las marcas necesitan cada vez más y por eso recurren a ellas". Por otra parte, Marcelo Sorzana - director de la consultora Surreal, señala que: "Suelen ser más informadas que formadas. Ellas manejan una info más efímera". Ambos hacen hincapié en la falta de formación, y exponen una realidad propia de su circuito de acción de los bloggers, cuando refuerza-Marcelo- la efemeridad como registro, casi una obviedad si se comprende que su lugar es la red y su tema, la moda.

Pero, no sólo los bloggers son convocados para protagonizar campañas publicitarias, sino también son citados en notas especializadas como voz autorizada sobre diferentes temáticas referidas al campo de la moda. Una de las precursoras en este sentido, como se mencionó anteriormente, es Lorena Pérez, la autora de Bloc de Moda ya cuenta con su columna de moda en un medio impreso, pero desde años atrás la citan como voz autoriza desde su rol de blogger. Así lo muestra la nota publicada por clarín.com Fashionistas: Predican moda las 24 horas y ya tienen miles de fieles, escita por la periodista Victoria De Masi, publicada en septiembre de 2012. La nota narra las aventuras de los fashionistas en Argentina y el impacto que tienen sus acciones. Entre las referencias que se destacan está la que refiere Lorena:

Ni frívolo ni exclusivamente femenino: los varones también participan. "Ellos están muy enganchados con esta tendencia. Su mirada es más profunda, concreta. Son grandes observadores. Rara vez se equivocan a la hora de comentar un estilo", asegura Lorena Pérez, de Bloc de Moda, sitio de referencia fashionista.

Como todo blogger que se precie de tal, Aninka también se ha vuelto una voz autorizada a la que se refiere en los medios especializados. Así lo corrobora la nota publicada en lanacion.com Marcas de ropa que copian, ¿rédito fácil o moda accesible?, escrita por la periodista Laura Reina, publicada en junio de este año. La nota trata sobre el interminable tema de la copia en la moda, entre otros comentarios se resalta el de la diseñadora local Vero Alfie, directora de Visiones Trends, que diferencia la copia de autor a la masiva:

Eso mismo resalta AninkaTokos, bloguera de moda a cargo del sitio Desde el vestidor."Con el tema de las copias tengo sentimientos encontrados -admite-. Por una parte, no me molesta que una marca local tome la idea de un producto o de una colección si es que se trata de algo que para mí, en su versión original, representa un gasto que no puedo siquiera considerar", dice y da como ejemplo el caso de una marca de carteras y sobres que tiene entre sus modelos estrella una copia exacta de una cartera de la colección Resort 2015 de Valentino. "En ese caso sé que no podré tener la Valentino, entonces prefiero la copia; de hecho celebro que exista porque esa cartera me parece preciosa y acá cuesta 10 veces menos que la original".

La diferencia, dice Aninka, "es cuando una marca local copia un diseño de afuera y lo pone a un precio diez veces mayor que el original". 
Con sello de autoridad desde el título, la nota publicada por ellitoral.com Consejos de expertas, escrita por Soledad Vottori publicada en septiembre de este año, repasa el evento realizado en Rivera Shopping y reafirma la noción que afirma en su título con la siguiente bajada:

En el marco de Ruta de la Moda 2015 Estilo Ribera que se realizó el pasado 16 de septiembre en el estacionamiento de Ribera Shopping (puerto de nuestra ciudad), consultamos a cuatro mujeres que marcan tendencia: la bloggera Marou Rivero, y las modelos Soledad Solaro, Pía Slapka y Cintia Garrido.

En el campo de la moda las modelos fueron las figuras a seguir allá por los noventa como lo fueron las estrellas de Hollywood en su época de oro, rol equiparado actualmente por una bloggera profesional.

\section{Reality Show Fashion Blogger}

Para terminar de cerrar su sello de autoridad, el canal E!Entertaiment Television lanzó en Octubre último un reality show sobre la vida de las bloggers más destacadas Australia. La emisión se emitó en argentina los días domingos por la tarde y trata sobre el hacer de los bloggers en el circuito agitado de la gestión de contenido online. El programa vende a la gestión de las bloggers de moda como reto el poder lograr hacer su tarea en la que se destaca la producción de modas, la asistencia a eventos y el armado de las relaciones públicas con otros medios, como por ejemplo, los medios gráficos.

\subsection{El camino inverso}

El fenómeno de los bloggers también llega a las publicaciones en formato libro. Sobre éstas hay tres tipos: instructivos, bloggers que escriben sobre estilo, y biográficos. Si bien no abundan los ejemplares, sobre los libros instructivos se puede mencionar el libro de español Javier Muñiz Blogs, trucos del blogger (2014) publicado por editorial Altaria, y cuenta con 311 páginas, destinado, según el autor, a centros de formación y autodidactas. El contenido está enfocado a plantillas WordPress. Entre las publicaciones de bloggers que comparten sus consejo, se puede mencionar el libro de la española Alexandra Pereira que se titula El Mundo De Lovely Pepa. Descubre El Lado Más Personal De La Bloguera De Moda (2013) publicado por la editorial Hércules de Ediciones, en donde comparte consejos sobre estilo como lo hace en su blog, y en la descripción sobre el contenido en sí se aclara que:

Como no podía ser de otro modo, el libro dedica también un extenso capítulo a analizar el fenómeno de los "blogs de moda" desde la experiencia personal de la autora. No hay que olvidar que Lovely Pepa es uno de los 20 blogs más seguidos del mundo. 
El libro de Alexandra va por su segunda edición, el último ejemplar se titula Simply Lovely Pepa (2015) publicado por editorial Planeta. Parte del texto de contratapa dice: "Por fin en tus manos la guía de estilo de la fashionblogger más seguida en las redes. Alexandra Pereira, autora del exitoso blog «Lovely Pepa»..."

En esta línea temática también se pueden mencionar las publicaciones en inglés de las bloggers referentes como Chiara Ferragni autora del blog The Blonde Salad, o el libro de Leandra Medine autora del blog ManRepeller. Ambas están en las listas de los 10 blogs de moda más visitados a nivel mundial. De estilo biográfico y también en inglés se puede mencionar el libro de la inglesa Alexa Chung -autora del blog alexachungblog.tumblr. com- que se titula It. El título refuerza el hacer de una chica, digamos que se mueve como pez en el agua pero en su hábitat es el ciberespacio.

Producto de la mediatización, la primera "it girl" fue la actriz de cine mudo Clara Bow encargada de construir los estereotipos de flapper y chica it allá por los años 20s. It girl es un término para una joven que posee la cualidad "It" ("eso"), la atracción absoluta. Y se le adjudica a la novelista británica Elinor Glyn la creación de la concepciónsobre "it" a principios del siglo XX. Elinor daba cuenta de que con "eso" las chicas ganaban a todos los hombres, tenía cierta posibilidad atracción. Atracción necesaria que tienen las chicas It de este siglo para atraer y mantener activos a miles de seguidores. Sólo en su cuenta de Instagram, Alexa cuenta con más de 1.939 .000 seguidores. La madurez del blogging señala la corroboración del blog como canal efectivo de comunicación, pero su estado podría además de afirmar su consolidación también anticipar su declive, cuestión que hasta ahora -esta práctica- ha sabido esquivar.

La madurez del blogging señala la corroboración del blog como canal efectivo de comunicación, pero su estado podría además de afirmar su consolidación también anticipar su declive, cuestión que hasta ahora - esta práctica- ha sabido esquivar.

\section{Lista de Referencias bibliográficas}

Aguilera, J. L. (2007). Breve aproximación a los blogs para unidades de información. Anuario thinkEPI, (1), 166-168.

Alberich i Pascual, J. (2004) El efecto Moebius (De pliegues y torsiones en la cultura digital) En Sanchez Navarro, Jordi (ed.) Realidad Virtual. Visiones sobre el ciberespacio. Barcelona, Devir 2004.

Aldea, P. G., Vidales, N. L., Y García, M. R. (2014). Tendencias de consumo de blogs entre los jóvenes universitarios españoles: radiografía de su "blogosfera". En Historia y Comunicación Social, N 18, pp. 503-518.

Bajtin, M. M. (1979) El problema de los géneros discursivos. México: Siglo XXI.

Barreiro, A. M. (1998) El concepto de moda. En La moda en las sociedades modernas. Editorial Tecnos: Madrid.

Barthes, R. (2003) El sistema de la moda y otros escritos. Argentina: Paidós Comunicación.

Bijker, W. E., 1995, "Of Bicycles, Bakelites and Bulbs. Towards a Theory of SociotechnicalChange”. $1^{\text {a }}$ ed. Cambridge: MIT press. En Estalella, A. (2006) La construcción de la 
blogosfera: yo soy mi blog (y sus conexiones). En La blogosfera hispana: pioneros de la cultura digital. Fundación France Telecom España.

Bourdieu, P (1979). La elección de la necesario, en La distinción. Taurus: Madrid.

Bourdieu P. y Passeron J. C. (1981). Fundamentos de una teoría de la violencia simbólica. En La reproducción: Elementos para una teoría del sistema de enseñanza. Laia: Barcelona.

Castelles, M. (2007, coomp. Denis de Moraes). Innovación, libertad y poder en la era de la información. Cap. 7. En Sociedad mediatizada. España: Editorial Gedisa.

Gómez del Río, G (2009). En la era de los fotolectos: estudio de caso Para Ti colecciones. Amazon: Buenos Aires.

DeRosnay, J. (2002). Un cambio de era. En Ramonet, I (2002) La post-televisión. Icaria editorial: Barcelona.

Edo, C. (2007). El lenguaje y los géneros periodísticos en la narrativa digital. Jornalismo Digital de TerceiraGeração, 7-23.

Estalella, A. (2006). La construcción de la blogosfera: yo soy mi blog (y sus conexiones). En La blogosfera hispana: pioneros de la cultura digital. Fundación France Telecom España, pp. 20-37.

Fernández, J. L. (2012). La captura de la audiencia radiofónica. Buenos Aires: Líber Editores.

Fernández, J. L. (2016). Plataformas mediáticas y nives de análisis.recuperado en: ttps:// revistas.ort.edu.uy/inmediaciones-de-la-comunicacion/article/view/2618

Freire, F. C. y Martínez, M. G. (sf) Los blogs más relevantes evolucionan hacia modelos de gestión colaborativa. Manuscrito.

García Canclini, N. (2007). Lectores, espectadores e internautas. Editorial Gedisa: Barcelona.

Gómez del Río, G. (2009). En la era de los fotolectos: estudio de caso Para Ti Colecciones. Manuscrito no publicado.

Gordo, M. (2012). Lo analógico, lo digital y la regulación de la cibercultura. En Teknokultura, N 9(2), pp. 141-147.

Lash, S. (2005). Crítica de la información. Cap. Formas tecnológicas de vida. Amorrortu/ editores.

Laver, J. (1995). Breve Historia del traje y la moda. (5ta edición). Madrid: Ediciones Cátedra.

Lannelongue (2008). Las secretos de la moda al descubierto. Barcelona: Editorial Gustavo Gili.

Lipovestky, G. (1994). La seducción de las cosas. En El imperio de lo Efímero: La modas y su destino en las sociedades modernas. (4ta ed.) Barcelona: Editorial anagrama.

Lurie, A. (1994). El lenguaje de la moda: una interpretación de las formas de vestir. Buenos Aires: Ediciones Paidós.

Márquez, D. F. (2008). En busca del sujeto extraviado: reflexiones en torno al estudio de blogs. Revista Dialogos de la comunicación, FELAFACS, (76).

Martín Barbero, J. (2000). Ensanchando territorios en comunicación/educación. En Valderrama, C. E. (ed.), Comunicación-Educación. Coordenadas, abordajes y travesías. Bogotá: DIUC-Siglo del Hombre.

Martín Barbero, J. (2007, coomp. Denis de Moraes) Tecnicidades, identidades, alteridades: desubicaciones y opacidades de la comunicación en el nuevo siglo. Cap. 7. En Sociedad mediatizada. España: Editorial Gedisa. 
Mattelart, A. (2002). La nueva comunicación. En Ramonet, I (2002) La post-televisión. Icaria editorial: Barcelona.

Noguera Vivo, J. M. (2008). La percepción mediática de los blogs: del miedo al intrusismo al intrusismo de los medios. Diálogos de la comunicación, (76), 10.

Orihuela, J. L. \& Cambronero, A. (2006). La revolución de los blogs: cuando las bitácoras se convirtieron en el medio de comunicación de la gente.

Pérez Tornero, J. M.; Tropea, F.; Sanagustín, P. y Costa P. O. (1992). Los agentes estimuladores del consumo. En La seducción de la opulencia: publicidad, moda y consumo. Buenos Aires: Ediciones Paidós Ibérica S.A.

Psicitelli, A. (2002). Ciberculturas 2.0: en la era de las máquinas inteligentes. Cap. La odisea de Napter. Los sistemas par-a-par y el rediseño de la libertad de los usuarios. Editorial Gedisa. Barcelona.

Psicitelli, A. (2005). Internet, la imprenta del siglo XXI. Cap. 3 Los weblogs ponen la red al servicio de todas las voces. Editorial Gedisa. Barcelona.

Quintas, S. D., \& Avendaño, M. D. (2014). La necesaria transformación de los géneros: del papel al ciberperiodismo. Historia y Comunicación Social, 18, 187-197.

Ramonet, I. (2002). La post-televisión. Capítulo: Una gran mutación. Icaria editorial: Barcelona.

Ruiz Molina, E. (s/f) Los blogs de moda en España: de la espontaneidad del usuario a la profesión de blogger. RUTA: revista universitària de treballsacadèmics, (5), 1-25.

Saltzman, A. (2004). El cuerpo diseñado: sobre la forma en el proyecto de la vestimenta. Buenos Aires: Paidós.

Salvarría, R. y Sancho, F. (2007). Del papel a la Web. Evolución y claves del diseño periodístico en internet. Diseño periodístico en internet, 207-239.

Saulquin, S. (2006). Introducción. Historia de la moda argentina: del miriñaque al diseño de autor. México: Emecé.

Saulquin, S. (2010). La muerte de la moda, un día después. Buenos Aires: Paidós.

Sexe, N. (2001). Diseño.com. Buenos Aires: Ediciones Paidós: estudios de comunicación.

Sexe, N. (2007). El vestido en el mundo de la comunicación masiva. En Casos de comunicación y cosas de diseño. Buenos Aires: Ediciones Paidós.

Sibilia, P. (2008). El show del Yo. En La intimidad como espectáculos. Buenos Aires: Fondo de Cultura Económica.

Technorati. (2013). Recuperado en: http://technorati.com/business/advertising/ Consulta, 27 de marzo de 2013.

Ureta, A. L (2005). El ciberperiodismo y la reconfiguración de los géneros en función del hipertexto. Universidad del País Vasco - UPV/EHU. Manuscrito sin publicar.

Ureta, A. L. (2011). Propuesta metodológica para una aproximación empírica a los géneros ciberperiodísticos. Zer-Revista de Estudios de Comunicación, 15(29).

Verón, E. (2004). Prensa gráfica y teoría de los discursos sociales: Producción, recepción, regulación", en Fragmentos de un tejido. Barcelona: Gedisa.

Vivo, J. M. N. (2008). La percepción mediática de los blogs: del miedo al intrusismo al intrusismo de los medios. Diálogos de la comunicación, (76), 10.

Zizek, S. (2010). El acoso de las fantasías. Cap. El Ciberespacio, o la intolerables cerrazón del ser. 
Abstract: Independent specialized platforms, also known as weblogs, emerge as a product of social practice (blogging). These platforms are no longer a novelty but rather a necessity of the digital communication circuit specialized in fashion. Weblogs are no longer exhausted in their communicative dimension but are key knots of the network that make up the network. Currently, based on its analysis, three fundamental questions could be systematized: the constant in its stylistic features, the potentiality as generators of quality content for the network and its modality of articulation in relation to the circuit to which they belong.

Keywords: blog - blogger - fashion - fashion marketing - entrepreneurs.

Resumo: As plataformas especializadas independentes, também conhecidas como weblogs emergem como produto de uma prática social (o blogging) Estas plataformas já não são uma novidade sina mais bem são uma necessidade do circuito de comunicação digital especializado em moda. Os weblogs já não se esgotam em sua dimensão comunicativa senão que são nós fundamentais do tecido que compõem a rede. Atualmente a partir de sua análise poderiam ser sistematizadas três questões fundamentais: a constante em seus rasgos estilísticos, a potencialidade como geradores de conteúdo de qualidade para a rede e sua modalidade de articulação em relação a o ao circuito ao que pertencem.

Palavras chave: blog - blogueiro - moda - marketing de moda - empresários.

[Las traducciones de los abstracts fueron supervisadas por el autor de cada artículo] 